\title{
Quality of Life of Patients After Acute Myocardial Infarction: A Scoping Review
}

\author{
Donny Nurhamsyah, Yanny Trisyani, Aan Nuraeni \\ Faculty of Nursing, Padjadjaran University \\ Email:
}

\begin{abstract}
Sudden deaths from acute myocardial infarction have been a current trend of health care problem of Indonesians. This condition may have impacted on the patient's quality of life. The aim of this literature review was to identify factors that affected quality of life patient after acute myocardial infarction event. This review used a scoping review method. Literature searching was conducted using Google Scholar, Pubmed and Science Direct utilizing keywords: acute myocardial infarction, quality of life and questionnaire. The inclusion criteria were quantitative or qualitative study, peer-reviewed, published in 2008 - 2018. There were 18,035 papers retreived, only 19 papers met the inclusion criteria. Data were analyzed using content analyses. The findings of this study indicate that the quality of life of patients has decreased after experiencing acute myocardial infarction. Quality of life is influenced by 5 major factors, namely biological factors, emotional factors, physical factors, social factors and psychometric factors. There are 5 major factors that are proven to still affect the quality of life of patients with acute myocardial infarction. Further research is needed to determine psychometric factors in influencing quality of life. The instrument that can be used is macnew quality of life after myocardial infarction because it meets the psychometric criteria.
\end{abstract}

Keywords: Acute myocardial infarction, factor affecting, quality of life. 
Donny Nurhamsyah : Quality of Life of Patients after Acute Myocardial Infarction

\section{Introduction}

Sudden deaths from acute myocardial infarction become a trend of health problems in the world now. Data showed that sudden cardiac death accounts for 300 to 400 thousand deaths in the United States each year and nearly half of these deaths occured in the pre-hospital scope (Zipes \& Wellens, 2013). Seventeen point seven (17.7) million people died annually from cardiovascular disease and $31 \%$ of deaths occurring at a global level were caused by cardiovascular (WHO, 2013). Acute myocardial infarction is one of the five manifestations of coronary heart disease that leads to necrosis of cardiac muscle cells due to sustained ischemia (Mendis et al., 2011). Coronary heart disease is a disorder of the heart's blood vessels that can cause ischemic heart tissue and usually will cause clinical symptoms such as chest pain or discomfort in the patient's chest (Ministry of Health of the Republic of Indonesi [MOHRI], 2013).

Myocardial infarction is the leading cause of morbidity and mortality worldwide with more than 3 million people per year estimated to experience ST-STI Myocardial Infarction (STEMI) and more than 4 million people experienced Non ST-Elevated Myocardial Infarction (NSTEMI) (Lapointe-Shaw \& Bell, 2014). The American Heart Association (AHA), (2017) issued a scientific statement that cardiovascular disease is a major cause of mortality for women in the United States and globally. Coronary heart disease occurs in 6.6 million women in the United States each year to affect mortality and morbidity. Nearly half of the 2.7 million people diagnosed with a history of acute myocardial infarction. Additionally, over 53,000 died from myocardial infarction and it was estimated that 262 thousand more women treated for Acute Corronary Syndrome (ACS) (Mehta et al., 2016).

Indonesia as one of the developing countries in the world also revealed that coronary heart disease is the highest cause of death in all age groups (MOHRI, 2017). Based on the data from basic health research in 2013 that the prevalence of coronary heart disease diagnosed by physician was $1.5 \%$ or about 2.650 .340 people. The highest incidence was in the age group of 65-74 years $(3.6 \%)$ and followed by age group of 75 years and over (3.2\%) (MOHRI, 2013). In West Java there were about $1.6 \%$ or 514,597 people diagnosed with coronary heart disease (MOHRI, 2014).

The high incidence of this disease can change the quality of life of the sufferer. Broadly there were 3 main domains that affect the quality of life of people who experience acute myocardial infarction, those were emotional condition, physical condition and social life. This is also supported by another study that found that the quality of life of patients with heart disorders was influenced by factors such as anxiety, depression, medical treatment of revascularization, family and religious support (Nuraeni, Mirwanti, Anna, Prawesti, \& Emaliyawati, 2016; Rosidawati, Ibrahim, \& Nuraeni, 2016). Various studies identified other factors influencing the quality of life of the patients, including age, psychological resilience when faced with stressors, educational level, economic condition, physical activity, adherence to therapy and therapy reminder support devices such as smartphones (Bahall \& Khan, 2018; Beckman et al., 2016; Benetti, Laura, Araujo, \& Zuianello, 2010; Johnston, Bodegard, Jerström, \& Åkesson, 2016; Kong, 2018).

The quality of life of patients with acute myocardial infarction is important to identify because it is feared that it will affect the patient's rehabilitation process. Research on the quality of life of patients with acute myocardial infarction and influencing factors has been carried out in several countries. Therefore, this literature study was conducted to determine the quality of life of patients with acute myocardial infarction and other factors that may prove to affect quality of life.

\section{Research Method}

This literature study was a scoping review. The literature search was conducted using Google Scholar, Pubmed and Science Direct databases. To ensure relevance to this literature study, the articles used were limited to articles published over the past 10 years, from 2008 to 2018. Articles obtained were 18,035 articles using the keywords of acute myocardial infarction, quality of life 
Donny Nurhamsyah : Quality of Life of Patients after Acute Myocardial Infarction

Table 1 Results of the Literature Search

\begin{tabular}{lccc}
\hline Database & $\begin{array}{c}\text { Number of articles } \\
\text { according to } \\
\text { keywords }\end{array}$ & $\begin{array}{c}\text { Number of articles } \\
\text { obtained }\end{array}$ & $\begin{array}{c}\text { Number of articles matched } \\
\text { the inclusion criteria }\end{array}$ \\
\hline Google Schoolar & 17,300 & 46 & 13 \\
\hline Pubmed & 510 & 20 & 4 \\
Science Direct & 225 & 12 & 2 \\
Total & $\mathbf{1 8 , 0 3 5}$ & $\mathbf{7 8}$ & $\mathbf{1 9}$
\end{tabular}

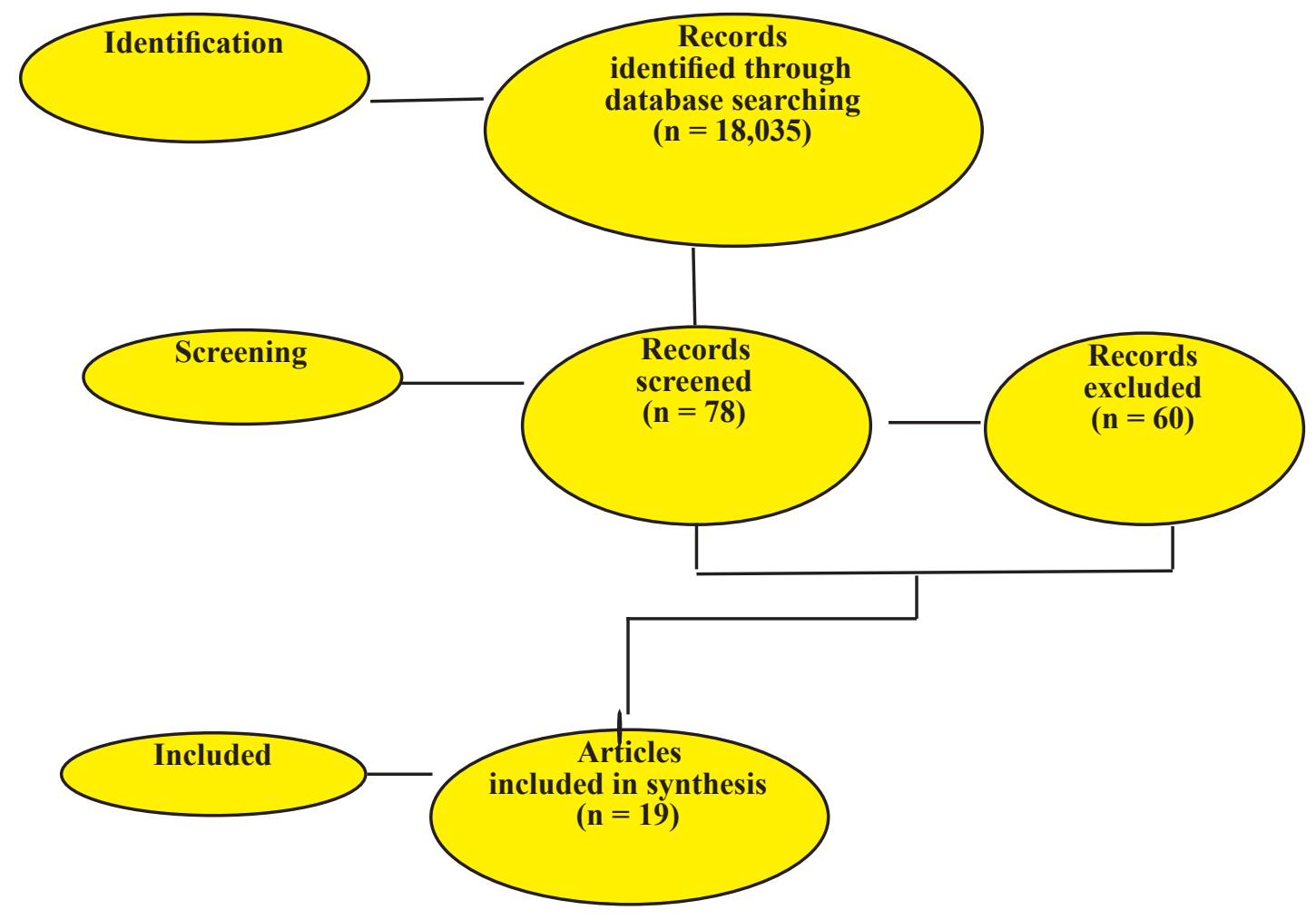

Figure 1 Literature Searching Flowchart 
Donny Nurhamsyah : Quality of Life of Patients after Acute Myocardial Infarction

and questionnaire. The inclusion criteria in this review were qualitative or quantitative research, peer-reviewed, full text, written in Indonesian and English and relevant to the topic of this review. After sorting out, 19 papers were found to meet the inclusion criteria. These 19 were further intensively read and analyzed using content analyses. Detailed search paths are presented in table 1 and figure 1.

\section{Research Result}

After conducting a critical appraisal on 18 articles, it was found that 15 of the articles employed questionnaires in the data collection related to the quality of life of patients with acute myocardial infarction. The types of questionnaires used to assess the quality of life of the patients were MacNew Quality of Life after Myocardial Infarction Questionnaire, Psychological resilience scale, self-efficacy scale, self-rating anxiety and Zung self-rating depression scale, VIRGO, SF-36, hospital anxiety, depression scale and Seattle Angina Questionnaire. The entire articles ultimately discussed factors influencing the quality of life of patients with acute myocardial infarction.

Studies regarding questionnaire being used to identify factors that affect the quality of life of patients with acute myocardial infarction were done in various countries across America, Europe and Asia. It was known that research about quality of life myocardial onfarction pastients has been done in some countries such as USA, Sweden, Singapore, Spain, Brazil, Netherlands, China, India, Austria and Indonesia (Table 2). The research types were quantitative and qualitative with various designs (Table 3).

Quality of Life of Patients with Acute Myocardial Infarction, the results obtained from many studies show that the excellent quality of acute myocardial infarction patients, after undergoing therapy, in the female sex, followed by comorbidities.

Table 2 Results of the Literature Search

\begin{tabular}{cc}
\hline Place of study & Number of articles \\
\hline USA & 6 \\
\hline Sweden & 2 \\
Spain & 1 \\
Brazil & 2 \\
Netherlands & 1 \\
China & 2 \\
India & 1 \\
Austria & 2 \\
Indonesia & 2 \\
Total & $\mathbf{1 9}$
\end{tabular}

Tabel 3 Research Design

\begin{tabular}{|c|c|c|}
\hline Place of study & Number of articles & Number of articles \\
\hline \multirow[t]{4}{*}{ Quantitative } & $\begin{array}{l}\text { Randomized Control Trial } \\
\text { (RCT) }\end{array}$ & 2 \\
\hline & Cross Sectional & 10 \\
\hline & Restrospective & 1 \\
\hline & Cohort/Prospective & 5 \\
\hline Qualitative & Epidemiological Study & 1 \\
\hline Total & & 19 \\
\hline
\end{tabular}

JNC - Volume 1 Issue 3 October 2018 
Donny Nurhamsyah : Quality of Life of Patients after Acute Myocardial Infarction

Factors that Influence the Quality of Life of Patients with Acute Myocardial Infarction, factors that affect the quality of life of patients can be broadly divided into 4 categories: biological factors, emotional factors, physical factors, social factors and psychometric factors (knowledge, attitudes, abilities and personality traits).

There were 2 articles using a randomized control trial design. Both studies suggest

\begin{tabular}{|c|c|c|c|c|}
\hline Author \& Year & Place of Study & Study Design & Sample & Instrument \\
\hline $\begin{array}{l}\text { (Höfer et al., } \\
2012)\end{array}$ & Austria & $\begin{array}{l}\text { Quantitative } \\
\text { (Cross Sectional) }\end{array}$ & $\begin{array}{l}276 \text { angina } \\
\text { patients and } \\
155 \text { ischemic } \\
\text { patients }\end{array}$ & $\begin{array}{l}\text { Administration } \\
\text { the of English-language } \\
\text { MacNew Heart Disease } \\
\text { HRQoL questionnaire in } \\
\text { 431 patients with heart } \\
\text { problems. }\end{array}$ \\
\hline (Kong, 2018) & China & $\begin{array}{l}\text { Quantitative } \\
\text { (Cross Sectional) }\end{array}$ & $\begin{array}{l}88 \text { AMI patients } \\
\text { after } \\
\text { intervention }\end{array}$ & $\begin{array}{l}\text { Providing questionnaires } \\
\text { on psychological resilience } \\
\text { scale, self-efficacy scale, } \\
\text { zung self-rating anxiety } \\
\text { scale and zung self-rating } \\
\text { depression scale. }\end{array}$ \\
\hline
\end{tabular}

(Mollon \& USA

Bhattacharjee, 2017)

(Beckman et al., USA 2016)
Quantitative (Retrospective)

441.456 patients (Datas

Risk Behavioral Risk Factor Surveillance $\mathrm{S}$ y $\mathrm{s}$ t e m (BRFSS) survey in 2015)

$\begin{array}{lll}\text { Quantitative } & 3.343 \text { patients } & \text { Using the VIRGO } \\ \text { (Cross Sectional) } & \text { post AMI } & \text { instrument (Variation in }\end{array}$ (Cross Sectional) recovery: role of gender on outcomes of young AMI patients) to determine sex differences and constraints in finances during the 12-month treatment and treatment process, patient health status, quality of life, stress and depression symptoms. The goal was to identify patients with bad conditions in order to determine other strategies.

\section{Results}

The English-language

HRNoL MacNew Heart

Disease questionnaire meets the psychometric criteria recommended for conceptual models, reliability, validity, interpretability and scale of load.

1. Psychological endurance and self-efficacy score of AMI patients after PCI varied significantly with age and economic status.

2. SAS scores and SDS values were significantly negatively correlated with psychological resilience and self-efficacy.

3. Negative emotions in AMI patients after PCI were closely related to psychological resilience and self-efficacy.

4. Anxiety and depression can be overcome by increasing psychological resilience and selfefficacy of patients undergoing PCI, so as to improve quality of life.

Survivors experienced a lower HRQoL on the domains of general health, physical health, daily activities and mental health than the general population. 
Donny Nurhamsyah : Quality of Life of Patients after Acute Myocardial Infarction

( J o h n s t o n, Sweden $\mathrm{B}$ o d e g a r d, Jerström, Åkesson, 2016)

(Bahall \& Khan, India 2018)

(Rodríguez-caulo Spain et al., 2018)

(Daniel et al., Sweden 2017)

(Oldridge, Cho, USA Thomas, Low, \& Höfer, 2017)

(Nogueira et al., Brazil 2008)

(Benetti, Laura, Brazil Araujo, \& Zuianello, 2010)
Quantitative (RCT)

treated patients

Quantitative 534

(Cross Sectional) patients

MI

17 randomly assigned to a group of patient support tools (intervention) and a simplified patient (control) patient group.

Then patient s'compliance with the use of ticagrelor were measured. .

On measurement it was also assessed the quality of life of patients using the European Quality of Life 5 Dimensions and patients satisfaction in using supporting device.

AMI The quality of life of patients with AMI were measured their using QLMI Questionaire
In MI patients the use of patient supporting tools improved adherence to drug therapy and increased patient healthy lifestyle.

. 
Donny Nurhamsyah : Quality of Life of Patients after Acute Myocardial Infarction

(Lee et al., 2014) China

(Gucht, 2004)

Netherlands

( A s a d i - lari, USA

Javadi, Melville,

Oldridge, \& Gray,

2003)

( F r i e d r i c h, Austria

Sipötz, Benzer,

Kunschitz,

Höfer, 2015)

(Pavy et al., 2015) USA

( $\mathrm{N} \mathrm{u}$ a e $\mathrm{n} \mathrm{i}$, Indonesia Mirwanti, Anna,

Prawesti, \&

Emaliy a w at i, 2016)

\section{Quantitative 210 \\ (Cross Sectional)}

patiens in

miokard infark

di China.

AMI Administering the MacNew

hearts questionnaire.

Quantitative 339 patients who A d m i n i s t e r i n g
( C o h o r t / came to hospital questionnaire to patients in ( $\mathrm{C}$ o h o
Prospective) for check up 3 and 12 months. after heart problems.

Quantitative 51 patients
(Cross Sectional)

A d m i n i s t e r i n g MacNew Persian version is questionnaire to 51 AMI comparable to English. This patients in cardiac care unit version has a high internal consistency and reasonable reproducibility.

Quantitative 1.012 patients All respondents filled the (Cross Sectional) from Spain and MacNew questionnaire 262 patients during hospitalization after from Austria PCI. tionaire has an acceptable reliability. So the questionnaire is good and ready to be used as a clinical assessment of myocardial infarction patients in mainland China.

MacNew in Dutch was proven to be substantially more responsive than the other two physical and psychological instruments.

The result that MacNew is globally advised to use but with the limitation that five items may be questionable in its scalability.
MacNew Hearth Disease In MSA it was advisable to distinguish between 6 items of ballast scale and 10 items of the emotion scale. This study showed that Mokken scale analysis could complement the results of factor analysis and might contribute to a more comprehensive understanding.

Quantitative 323 patients All patientsfilled the French MacNew in French is (Cross Sectional) who could speak version of MacNew, SF36, recommended to be an assessment French and the Hospital Anxiety and Depression Scale

form to evaluate the quality of life of patients with heart disorders who speak French.

Quantitative 100 patients All respondents filled a The end result that factors that (Cross Sectional) $\mathrm{r}$ a n d o m l y questionnaire about the affect the quality of life of recruited within factors and quality of life. patients with CHD is anxiety, 1 month of cardiac poly. depression and revascularization. With details:

1. CHD patients who do not experience anxiety quality of life 4.7 times better than anxious patients.

2. Patients who are not depressed better 5.4 times than the depressed.

3.Patients undergoing revascularization 3.23 are better than not. 
Donny Nurhamsyah : Quality of Life of Patients after Acute Myocardial Infarction

( R o s id aw at i, Indonesia Ibrahim, \& Nuraeni, 2016) \&

\&
(1)

\author{
Qualitative 6 patients after \\ (Semi Structure CABG \\ Interview)
}

Conducting a semi structural interview based on short form (SF- 36) instrument on quality of life of post-CABG patients.
(Spertus et al., Washington 1995)

$\begin{array}{ll}\text { Quantitative } & 4 \text { group patients: Serial } \\ \text { (Cross Sectional) } & 70 \text { undergoing of the seattle angina } \\ \text { e c e c c e questionnaire. } & \text { treadmill testing, } \\ & 58 \text { undergoing } \\ & \text { c o r o a r y } \\ & \text { angioplasty, 160 } \\ & \text { with initialty } \\ & \text { stable coronary } \\ & \text { artery disease } \\ & \text { and an additional } \\ & \text { 84 with coronary } \\ & \text { artery disease. }\end{array}$
were free from the disease. 3. Socially all participants revealed that family support and support of people around was needed.

4. Spiritually, participants felt closer to God and more grateful for the situation.

1. Physically the participants still felt the pain of surgery such as tingling and numbness, but not to interfere with daily activities.

2. Emotionally all participants expressed happiness because they 1.

Questionnaire respons of patients with stable coronary artery disease did not change over 3 months.

2. The questionnaire was sensitive to both dramatic clinical change, as seen after successful coronary angioplasty and more subtle clinical change, as seen among outpatients with initially stable coronary artery disease. that the quality of life of patients with acute myocardial infarction may increase due to the use of supportive tools in therapy and ministernotomy measures. Other 16 articles using a cross-sectional design, retrospective, cohort and epidemiological study reported that by administering a questionnaire to evaluate the quality of life of patients after myocardial infarction, most studies found that the quality of life of patients affected by various factors such as age, education, economic status, physical activity, psychological, medication adherence, anxiety, depression, medical, cultural, religious, emotional, social and psychometric factors.

\section{Disccusion}

Quality of Life for Patients with Acute Myocardial Infarction

This literature study reveals that the quality of life of patients with acute myocardial infarction is still an interesting thing to uncover. The quality of life of patients is strongly influenced by various conditions. This opinion is evidenced by the many findings that say that the quality of life of patients with acute myocardial infarction is still low. This is in accordance with research conducted by Kong (2018) in China found that the decline in quality of life of patients due to negative emotional conditions in patients after doing percutaneous coronary intervention related to psychological endurance and self efficacy. This is reinforced by research conducted by Mollon and Bhattacharjee (2017) in the USA found that patients who survived the attack of acute myocardial infarction experienced a low quality of life in the domain of general health, physical, mental and daily activities compared to the general population. In addition, female gender has decreased quality of life after acute myocardial infarction due to financial constraints (Beckman et al., 2016).

Different findings were expressed by Johnston et al., (2016) that patients who received smartphone-based support in reminding therapy schedules experienced increased adherence and an increase in lifestyle which ultimately affected an improved quality of life.

Factors Affecting the Quality of Life of Acute Myocardial Infarction Patients

Biological Factors

Biological factors that affect the quality 
Donny Nurhamsyah : Quality of Life of Patients after Acute Myocardial Infarction

of life of patients with acute myocardial infarction are the sex and age of the patient. This is consistent with research conducted by Beckman et al. (2016) stating that female sex experiences a low quality of life because women experience more financial difficulties. This is reinforced by research Hajian-Tilaki, Heidari, and Hajian-Tilaki (2017) which states that female gender has a lower quality of life score than men due to sociodemographic conditions and chronic diseases. In addition to gender, age also affects the quality of life of patients. Kong (2018) states that age can affect quality of life due to the level of psychological endurance and endurance and self efficacy.

These findings have proven that biological factors greatly affect the quality of life conditions of patients with acute myocardial infarction.

\section{Emotional Factors}

Emotional factors that affect the quality of life of patients with acute myocardial infarction consist of mental conditions, psychological endurance, self efficacy, anxiety and depression. This is in accordance with research conducted by Kong (2018) that psychological resilience and selfefficacy will affect the patient's emotional state towards a negative direction so that it also negatively impacts the patient's quality of life. Daniel et al. (2017) also said that patients who experience acute myocardial infarction experience physical and mental stress starting from 6 weeks to 3 months after the event. Nuraeni et al. (2016) revealed that anxiety and depression are negative factors that cause low quality of life. But other studies have revealed qualitatively that patients who have finished surgery on the heart arteries say that emotionally all participants expressed a feeling of happiness because they were free from their illness.

These findings are able to explain openly that emotional factors also greatly affect the quality of life of patients with acute myocardial infarction. Quality of life can be good if the patient has a good coping mechanism in accepting his condition.
Physical Factors

Physical factors that affect the quality of life of patients with acute myocardial infarction consist of physical health conditions, inability to visit health care centers, exercise capacity and ability to work. This is in line with research conducted by Benetti et al. (2010), Nogueira et al. (2008), Daniel et al. (2017), Bahall and Khan (2018), and Mollon and Bhattacharjee (2017). According to Benetti et al. (2010) exercises with greater intensity can produce functional capacity and quality of life for patients after an attack. This is reinforced by Daniel et al. (2017) that exercise capacity can improve the quality of life of patients even though the duration is longer 6 weeks to 3 months after the attack. Another finding according to Nogueira et al. (2008) states that the quality of life of patients is getting better and is followed by the return of the patient working like before getting sick. This is also in line with Bahall and Khan (2018) which states that the physical domain of the quality of life of patients without other diseases has increased.

Other opinions differ, according to Mollon and Bhattacharjee (2017) that patients who have just experienced an attack have a lower quality of life when compared to patients with a general disease population.

These findings further reinforce that physical factors have a large influence on improving the quality of life of patients with acute myocardial infarction. However, based on these findings, time is a determining factor in the quality of life of patients.

\section{Social Factors}

Social factors can also affect the quality of life of patients with acute myocardial infarction including family support, support for people around and use of smartphone aids to improve therapy adherence. This was expressed by Rosidawati et al. (2016) with qualitative methods that support the family and the people around them is needed by patients to improve their quality of life. Johnston et al. (2016) also said that with the provision of communication support through Smarthphone, compliance in carrying out patient therapy increased and was accompanied by the patient's lifestyle. 
Donny Nurhamsyah : Quality of Life of Patients after Acute Myocardial Infarction

These findings further reinforce that the social life of patients greatly influences the quality of life of patients. Humans as social beings will feel more confident facing their conditions when the surrounding environment provides support.

Psychometric factors

Based on the review, 4 factors have been mentioned previously, there is one factor that still cannot be revealed through researches. These factors are psychometric factors. Psychometric factors are branches of science from psychology which aim to measure the patient's knowledge, attitudes, abilities and personality traits. According to Supratiknya (2014) psychometric measurements need to be done because they can analyze "individual differences". This factor is interesting, but there has not been much research on the quality of life of patients with acute myocardial infarction associated with psychometric factors. According to Kimble et al. (2002) which examined the seattle instrument angina questionnaire stated that this instrument could not describe in detail the psychometric criteria. Meanwhile, according to Höfer et al. (2012) which examined the instrument macnew quality of life after myocardial infarction stated that this instrument can meet the shortage of other instruments, namely measuring psychometric criteria.

This finding adds to the new knowledge that must be revealed. It is necessary to do research on this factor actually able or not to affect the quality of life of patients with myocardial infarction.

\section{Conclussion}

Based on the review carried out concluded that a person's quality of life has decreased after experiencing acute myocardial infarction. The decreasing quality of life of patients with acute myocardial infarction is influenced by 5 major factors, namely biological factors, emotional factors, physical factors, social factors and psychometric factors. The five major factors affect the quality of life of patients from different points of view. This literature study shows that the quality of life of patients with acute myocardial infarction is still in the low category. This can happen because humans are different beings from one another.

Based on this literature study, it is necessary to conduct further research on psychometric factors that affect the quality of life of patients with acute myocardial infarction. Psychometric factors have not been identified for the condition of patients in Indonesia. To examine psychometric factors in patients with acute myocardial infarction can be done by using the macnew quality of life after myocardial infarction instrument because it meets these criteria.

\section{References}

Asadi-lari, M., Javadi, H.R., Melville, M., Oldridge, N.B., \& Gray, D. (2003). Adaptation of the MacNew quality of life questionnaire after myocardial infarction in an Iranian population, 6, 1-6.

Bahall, M., \& Khan, K. (2018). Quality of life of patients with first-time AMI: A descriptive study, 1-10.

Beckman, A.L., Bucholz, E.M., Zhang, W., Xu, X., Dreyer, R.P., Strait, K.M., ..., Spatz, E.S. (2016). Sex differences in financial barriers and the relationship to recovery after acute myocardial infarction. American Heart Journal, 1-15. https://doi.org/10.1161/ JAHA.116.003923.

Benetti, M., Laura, C., Araujo, P. De, \& Zuianello, R. (2010). Original article cardiorespiratory fitness and quality of life at different exercise intensities after myocardial infarction, 399-403.

Daniel, M., Agewall, S., Caidahl, K., Collste, O., Ekenbäck, C., Frick, M., ..., Henareh, L. (2017). Effect of myocardial infarction with nonobstructive coronary arteries on physical capacity and quality-oflife. The American Journal of Cardiology, 120(3), 341-346. https://doi.org/10.1016/j. amjcard.2017.05.001. 
Donny Nurhamsyah : Quality of Life of Patients after Acute Myocardial Infarction

Friedrich,O., Sipötz, J.,Benzer,W.,Kunschitz, E., \& Höfer, S. (2015). The dimensional structure of the MacNew Health Related Quality of Life questionnaire: A Mokken Scale Analysis. Journal of Psychosomatic Research, 79(1), 43-48. https://doi. org/10.1016/j.jpsychores.2015.04.007.

Gucht, D. (2004). Quality of life after myocardial infarction: Translation and validation of the MacNew Questionnaire for a Dutch population, (Mi), 1483-1488.

Hajian-Tilaki, K., Heidari, B., \& HajianTilaki, A. (2017). Are gender differences in health-related quality of life attributable to sociodemographic characteristics and chronic disease conditions in elderly people?. International Journal of Preventive Medicine, 8, 95. https://doi.org/10.4103/ ijpvm.IJPVM_197_16.

Höfer, S., Saleem, A., Stone, J., Thomas, R., Tulloch, H., \& Oldridge, N. (2012). The MacNew heart disease health-related quality of life questionnaire in patients with angina and patients with ischemic heart failure. Value in Health, 15(1), 143-150. https://doi. org/10.1016/j.jval.2011.07.003.

Johnston, N., Bodegard, J., Jerström, S., \& Åkesson, J. (2016). Effects of interactive patient smartphone support app on drug adherence and lifestyle changes in myocardial infarction patients: A randomized study. American Heart Journal, 178, 85-94. https:// doi.org/10.1016/j.ahj.2016.05.005.

Kimble, L.P., Dunbar, S.B., Weintraub, W.S., McGuire, D.B., Fazio, S., De, A.K., \& Strickland, O. (2002). The seattle angina questionnaire: Reliability and validity in women with chronic stable angina. Heart Disease, 4(4), 206-211. https://doi. org/10.1097/00132580-200207000-00002.

Kong, L. (2018). Correlations among psychological resilience, self-efficacy, and negative emotion in acute myocardial infarction patients after percutaneous coronary intervention, 9 (January), 1-7. https://doi.org/10.3389/fpsyt.2018.00001.
Lee, A., Studies, N., Loo, Y., Lee, A., Studies, N., Loo, Y., ..., Loo, Y. (2014). Psychometric testing of the Chinese Mandarin version of the MacNew Heart Disease Health-related Quality of Life questionnaire for patients with myocardial infarction. https://doi. org/10.1111/ijn.12238.

Mollon, L., \& Bhattacharjee, S. (2017). Health related quality of life among myocardial infarction survivors in the United States: A propensity score matched analysis, 1-10. https://doi.org/10.1186/s12955-0170809-3.

Nogueira, C.R.S.R., Hueb, W., Takiuti, M.E., Girardi, P.B.M.A., Nakano, T., Fernandes, F., ..., Stolf, N.A. (2008). Original article quality of life after on-pump and off-pump Coronary Artery Bypass Grafting Surgery, 217-222.

Nuraeni, A., Mirwanti, R., Anna, A., Prawesti, A., \& Emaliyawati, E. (2016). Faktor yang memengaruhi kualitas hidup pasien dengan penyakit jantung koroner (Factors influenced the quality of life among patients diagnosed with coronary heart disease), 4, 107-116.

Oldridge, N., Cho, C., Thomas, R., Low, M., \& Höfer, S. (2017). Validation of the English Version of the HeartQoL Health-Related Quality of Life Questionnaire in patients with Coronary Heart Disease, 53217, 1-8. https:// doi.org/10.1097/HCR.0000000000000248.

Pavy, B., Iliou, M., Höfer, S., Vergès-patois, B., Corone, S., Aeberhard, P., ..., Oldridge, N. (2015). Validation of the French version of the MacNew heart disease health-related. Archives of Cardiovascular Diseases, 108(2), 107-117. https://doi.org/10.1016/j. acvd.2014.09.006.

Rodríguez-caulo, E.A., Guijarro-contreras, A., Otero-forero, J., Mataró, M.J., Sánchezespín, G., Guzón, A., ..., Jiménez-navarro, M. (2018). Quality of life, satisfaction and outcomes after ministernotomy versus full sternotomy isolated aortic valve replacement (QUALITY-AVR): Study protocol for a randomised controlled trial, 1-8. 
Nabila Rahma Nur : Women's Intrinsic Motivation in Conducting Breast Self-Examination

Rosidawati, I., Ibrahim, K., \& Nuraeni, A. (2016). Kualitas hidup pasien pasca Bedah Pintas Arteri Koroner (BPAK) (Quality of life among patients with post Coronary Artery Bypass Surgery), 4, 151-161.

Spertus, J.A., Winder, J.A., Dewhurst, T.A., Deyo, R.A., Prodzinski, J., McDonnell, M., \& Fihn, S.D. (1995). Development and evaluation of the seattle angina questionnaire: A new functional status measure for coronary artery disease. Journal of the American College of Cardiology, 25(2), 333-341.https:// doi.org/10.1016/0735-1097(94)00397-9.

Supratiknya, A. (2014). Pengukuran psikologis. Universitas Sanata Dharma. 